\title{
Reconstruction of Temperature and Salinity in the Upper Layer of the Black Sea Using Pseudo-Measurements on the Underlying Horizons
}

\author{
P. N. Lishaev*, V. V. Knysh, G. K. Korotaev \\ Marine Hydrophysical Institute of RAS, Sevastopol, Russian Federation \\ *pavellish@mail.ru
}

\begin{abstract}
Introduction. Using the original method consisting in the combined analysis of altimetry data and scanty measurements by the Argo buoys, three-dimensional fields of the temperature and salinity pseudomeasurements were previously reconstructed at the 63-500 m layer horizons, at that the areas to the right of the Rim Current and in the anticyclonic eddies up to the $125 \mathrm{~m}$ depth remained unfilled.

Data and methods. The algorithm for restoring the unfilled areas by replenishing them with the seawater salinity and temperature values within the layer $2.5-125 \mathrm{~m}$ (using the altimetry and the Argo data for 2012 as an example) is proposed. The daily-average salinity (temperature) in the $2.5-125 \mathrm{~m}$ layer was reconstructed by correcting the model-predicted salinity (temperature) through the weighted data of its deviations from the pseudo-measurements carried out on the underlying baseline. $150 \mathrm{~m}$ horizon was assumed to be the main baseline for which pseudo-measurements are available on the entire horizon of the sea. The weighting factors are determined by the salinity (temperature) covariance functions of the baseline with the model salinity (temperature) on the overlying horizons. The iterative procedure was used to reconstruct the salinity and temperature pseudo-measurements.

Results. Comparison of the root-mean-square deviations of the reconstructed salinity fields from the measured ones and its variability showed that in the halocline on the $88 \mathrm{~m}$ horizon, its variability was 1.9 times higher than the salinity deviations. Variability of the measured temperature on the $88 \mathrm{~m}$ horizon was 1.5 times higher than the deviations of the reconstructed temperature fields. The reconstructed fields of the salinity (temperature) pseudo-measurements were assimilated in the model of the Marine Hydrophysical Institute (MHI) by the adaptive statistic method for reanalysis of the Black Sea fields for 2012. The temperature and salinity fields reconstructed in reanalysis were validated. The cold intermediate layer (CIL) is well reproduced; its temperature is slightly understated. The satellite measurements of the sea surface temperature should be necessarily assimilated in the circulation model. The sea level in the deep-water area reconstructed in reanalysis was quite close to the altimetry one.

Discussion and conclusion. Three-dimensional fields of temperature and salinity in the main pycnocline are reconstructed with sufficiently high accuracy in the deep-water part of the Black Sea. The seawater temperature in the surface layer $0-40 \mathrm{~m}$ cannot be reconstructed with acceptable accuracy. The approaches proposed in the previous studies and in the present paper can be effective for the other marine areas like the marginal seas of the oceanic type and the oceanic eddies, where relatively homogeneous water masses are observed.
\end{abstract}

Keywords: pseudo-measurements of salinity and temperature, altimetry, Argo floats, base horizon, covariance functions, reanalysis, adaptive statistic.

Acknowledgments: the results of the investigation carried out in the section "Procedure of reconstructing the three-dimensional fields of the salinity and temperature pseudo-measurements in the 2.5-125 m layer" are obtained within the framework of the state task on theme No. 0827-2014-0011 "Investigation of the regularities in changes of the marine environment state based on the operational observations and the data of the system of nowcast, forecast and reanalysis of the marine water areas state". The rest of the results represented in the paper were obtained at financial support of the Russian Scientific Foundation grant (project No. 17-77-30001) and the RFBR grant No. 16-05-00264 A.

For citation: Lishaev, P.N., Knysh, V.V. and Korotaev, G.K., 2019. Reconstruction of Temperature and Salinity in the Upper Layer of the Black Sea Using Pseudo-Measurements on the Underlying Horizons. Physical Oceanography, [e-journal] 26(2), pp. 104-122. doi:10.22449/1573-160X-2019-2-104-122

DOI:10.22449/1573-160X-2019-2-104-122

(C) 2019, P. N. Lishaev, V. V. Knysh, G. K. Korotaev

(C) 2019, Physical Oceanography 


\section{Introduction}

An important task of operational oceanology is ocean data (contact and remote) assimilation in water circulation models for carrying out the reanalysis of the World Ocean state and its separated components. An example of the implementation of such a task is GODAE international program [1]. It is the combined use of contact and remote data of high spatial and temporal resolution in the models that makes it possible to describe ocean variability on the required scales.

Nowadays, for the Black Sea there are several products for retrospective analysis of hydrophysical fields for different time intervals. In [2], the reanalysis for 1993-2012 period was carried out on the basis of the model with $5 \times 5 \mathrm{~km}$ spatial resolution set out in [3]. Satellite measurement data (sea surface temperature, level anomalies), as well as temperature and salinity profiles at depths below $200 \mathrm{~m}$, which describe the climatic seasonal variation, were assimilated in the model. It seems that more accurate account of the basin stratification variability by the space could improve the reanalysis quality.

In [4], NEMO v3.4 model with $3 \mathrm{~km}$ spatial resolution was applied, 1992-2017 reanalysis time interval was used. To assimilate the data on the surface temperature, level anomalies and profiles of salinity and temperature obtained by Argo buoys [5], 3D-Var scheme was applied. However, due to the limited hydrological measurements, the use of 3D-Var procedure leads to significant discrepancies.

For qualitative simulation of thermohaline stratification and mesoscale processes, it is important to assimilate observational data, uniformly distributed over the water area of the basin under study.

The original technique for reconstructing daily temperature (salinity) fields at 100-500 m layer horizons of the basin deepwater part, limited to $500 \mathrm{~m}$ isobath, was proposed in [6,7]. It is based on a combined analysis of altimetry and numerically insignificant ship hydrological observations in the Black Sea over 1993-2002. This technique was refined and applied in [8] to the salinity and temperature measurements carried out by Argo buoys. This provided the reconstruction of three-dimensional fields of temperature and salinity pseudomeasurements on a regular grid in 63-500 m layer over 1993-2014.

Positive quality of the developed technique is the fact that the horizontal structure of the fields of salinity and temperature pseudo-measurements at all horizons in 63-500 m layer for each day during 1993-2014 period is similar to the altimetric sea level topography and reflects the main synoptic processes. However, due to the technique peculiarity, the salinity (temperature) values are not reconstructed at certain horizons of 63-125 m layer to the right from the Black Sea Rim Current (RC) front and in anticyclonic eddies (Fig. 9 in [7]). The presence of unfilled zones in the considered deepwater area of the sea is explained by the fact that, according to our technique, the upper boundary for the reconstruction of temperature and salinity profiles is linked to an isopycnic surface.

In [9], a reanalysis of the Black Sea hydrophysical fields over 1993-2014 period with the assimilation of the above-described three-dimensional temperature fields in the Marine Hydrophysical Institute (MHI) model [10] with $5 \times 5 \mathrm{~km}$ resolution was performed. In general, as a result of reanalysis we obtained 
a satisfactory correspondence between the temperature and salinity fields calculated by the model. The fields were obtained from the observations performed by profiling floats within the main pycnocline. At the same time, the deviation of temperature and salinity calculated values was significant in the upper layers of the sea. In addition, the level field, constructed as a result of reanalysis, had smaller amplitude in comparison with the observations. This led to an underestimation of the velocity of geostrophic currents in the sea upper layers.

The work [11], in which the problem of variation assimilation of the Black Sea surface temperature satellite measurement data in $\sigma$-coordinate model [12] for reconstructing the heat fluxes was solved, is an exemplary one in this regard. The analysis of temperature profiles at various points of the sea showed that temperature is not only refined at the sea surface, but also at the horizons of layer 2, 5-30 m. Specificity of our algorithm for reconstructing the temperature and salinity pseudo-measurements at 2.5-50 m layer horizons (see below) consists in the fact that these fields are calculated according to the data from the underlying basic horizons.

This work is a continuation of the studies performed in [9, 13]. Its aim is the development of the algorithm proposed in these works in order to achieve higher reanalysis accuracy of the Black Sea fields in its upper active layer. In this regard, we propose a procedure for supplementing previously obtained profiles with missing temperatures and salinity values in 63-125 m layer in the area to the right of the Black Sea RC front and anticyclonic eddies. This procedure also provides a reconstruction of the profiles of temperature and salinity pseudo-measurements (according to the measurement data over 2012 itself) in upper 2.5-63 m layer.

\section{Basic relations for reconstructing three-dimensional fields of the sea temperature and salinity pseudo-measurements in 2.5-125 m layer}

In order to reconstruct the salinity profiles in 2.5-125 layer, methodologic principles of optimal interpolation [14] were used. For finding interpolation weights, it is necessary to know the autocorrelation functions of thermohaline fields and their measurement errors.

Autocorrelation function of the salinity field (temperature), taking into account its normalization, can be represented as follows [13]:

$$
P_{\mathrm{S}}\left(\vec{x}, \vec{x}^{\prime}, t\right)=\sigma_{S}(\vec{x}, t) \sigma_{S}\left(\vec{x}^{\prime}, t\right) P_{S}^{u}\left(\vec{x}, \vec{x}^{\prime}, t\right),
$$

where $\sigma_{S}(\vec{x}, t), \sigma_{S}\left(\vec{x}^{\prime}, t\right)$ are root-mean-square deviations (RMSD) of salinity (temperature); $\vec{x}=(x, y, z) ; x$ axis is directed to the east, $y$-to the north, $z$-vertically downwards; $P_{S}^{\mu}\left(\vec{x}, \vec{x}^{\prime}, t\right)$ is a normalized autocorrelation function of salinity (temperature) field. In this work, salinity (temperature) in 2.5-125 layer is reconstructed by means of correction of predictive three-dimensional salinity (temperature), calculated in the model, at the horizons of considered layers by the data of its pseudo-measurements from the underlying basic horizon. Therefore, we focus on the salinity field covariances along the vertical coordinate with regard to the results of $[15,16]$, in which the model salinity (temperature) correction by 
altimetry data was carried out. For this purpose we make the following assumptions for the factors from the right side of relation (1):

$$
\begin{gathered}
\sigma_{S}(\vec{x}, t) \cong \sigma_{S}\left(z_{*}, t\right), \\
\sigma_{S}\left(\vec{x}^{\prime}, t\right) \cong \sigma_{S}\left(z_{k}, t\right), \\
P_{S}^{H}\left(\vec{x}, \vec{x}^{\prime}, t\right) \cong P_{S}^{H}\left(z_{*}, z_{k}, t\right) P_{S}^{H}\left(\left|x-x^{\prime}\right|,\left|y-y^{\prime}\right|, z_{*}, t\right) .
\end{gathered}
$$

Here $z_{*}$ is the first of the model horizons from the sea surface (basic horizon) at which "empty" areas in the daily three-dimensional fields of salinity pseudomeasurements [7], reconstructed by original technique, are absent; $z_{k}$ are those of overlying horizons (relating to the basic one) at which the salinity pseudomeasurements should be reconstructed; $P_{S}^{\mu}\left(z_{*}, z_{k}, t\right)$ is a normalized function of $z_{*}$ basic horizon salinity pseudo-measurements covariance with model salinity at $z_{k}$ overlying horizons; $P_{S}^{\mu}\left(\left|x-x^{\prime}\right|,\left|y-y^{\prime}\right|, z_{*}, t\right)$ is a normalized autocorrelation function of salinity pseudo-measurements at $z_{*}$ horizon, depending on the distance between the nodes of the model grid domain. Approximating functions in the expressions (2) - (4) are considered to be known. The salinity pseudo-measurements at $z_{*}$ basic horizon are considered to be independent in each grid node in the first approximation.

As the basic horizon we took $z_{*}=150 \mathrm{~m}$ one, for which the pseudomeasurements on the entire sea area are available. In this case, the formula for salinity pseudo-measurements reconstruction in the sea deepwater area at $z_{k}$ horizons in $i, j$ nodes has the following form:

$$
S_{i, j}^{\text {reconst }}\left(z_{k}, t_{l}\right)=S_{i, j}^{\text {prog }}\left(z_{k}, t_{l}\right)+\frac{\sigma_{S}\left(z_{*}, t_{l}\right) \sigma_{S}\left(z_{k}, t_{l}\right) P_{S}^{H}\left(z_{*}, z_{k}, t_{l}\right)}{\sigma_{S}^{2}\left(z_{*}, t_{l}\right)+\sigma_{\text {errS }}^{2}\left(z_{*}, t_{l}\right)}\left[S_{i, j}^{\text {pseudo }}\left(z_{k}, t_{l}\right)-S_{i, j}^{\text {pseudo }}\left(z_{k}, t_{l}\right)\right],
$$

where $k$ denotes the numbers of horizons (from 1 to 15 ) on $z$ axis at 2.5-125 m inclusive; time $t_{l}(l=1,2, \ldots)$ is measured in days; $\sigma_{\mathrm{S}}^{2}\left(z_{*}, t_{l}\right)$ is a dispersion od salinity pseudo-measurements at the basic horizon; $\sigma_{e r r S}^{2}\left(z_{*}, t_{l}\right)$ is a dispersion of "measurement" errors at $z_{*}$ horizon. A numerator is non-normalized function of the salinity covariance $P_{S}\left(z_{*}, z_{k}, t_{l}\right)$.

An assessment of the salinity pseudo-measurements covariance function at $z_{*}$ horizon with the model salinity at overlying $z_{k}$ horizons was carried out as follows:

$$
P_{S}\left(z_{*}, z_{k}, t_{l}\right)=\frac{1}{N-1} \sum_{i, j} \delta S_{i, j}\left(z_{*}, t_{l}\right) \delta S_{i, j}\left(z_{k}, t_{l}\right) .
$$

Here $N$ is a number of grid nodes at 2.5-150 m layer horizons in the deepwater sea area,

$$
\begin{gathered}
\delta S_{i, j}\left(z_{*}, t_{l}\right)=S_{i, j}^{\text {pseudo }}\left(z_{*}, t_{l}\right)-\bar{S}^{\text {pseudo }}\left(z^{*}, t_{l}\right) \\
\delta S_{I, j}\left(z^{*}, t_{l}\right)=S_{I, j}^{\text {prog }}\left(z_{*}, t_{l}\right)-S^{\text {prog }}\left(z *, t_{l}\right)
\end{gathered}
$$

the line denotes averaging over horizon. 
Formula (1), assumptions (2) - (4) and expressions (5) - (8) have the same form for the temperature.

\section{Procedure for reconstructing three-dimensional fields of the sea salinity and temperature pseudo-measurements in 2.5-125 m layer}

Reconstruction of the fields of thermohaline parameters pseudo-measurements in the deepwater sea area were performed by iteration. The procedure of iterative salinity (temperature) reconstruction is selected in order to use higher values of weight factors in formula (5) (Fig. 1).
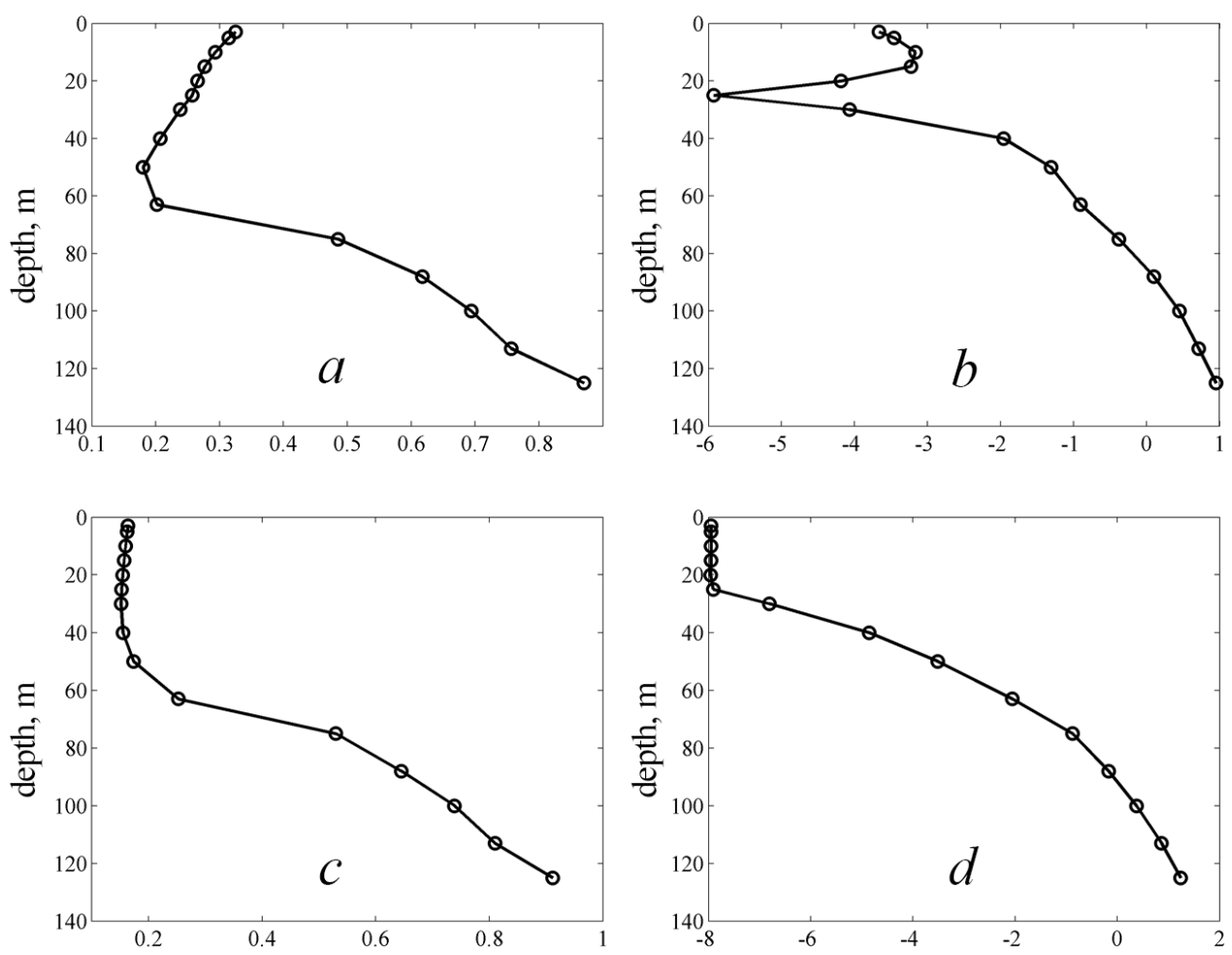

F i g. 1. Dependence of the season-average weighting coefficients on depth for salinity $(a, c)$ and temperature $(b, d)$ in summer $(a, b)$ and winter $(c, d), 2012$

In the first iteration, daily salinity (temperature) pseudo-measurements are reconstructed in 63-125 $\mathrm{m}$ layer in the nodes that belong only to the zones located to the right of the Black Sea RC front and anticyclonic eddies, as well as at the horizons of 2.5-50 m layer in all model grid nodes. In this case we use: an initial field of salinity (temperature) pseudo-measurements at $150 \mathrm{~m}$ basic horizon, its calculated dispersion $\sigma_{S}^{2}\left(z_{*}, t_{l}\right)$ (the dispersion of "measurement" errors was assumed to be equal to $\left.0,05 \sigma_{S}^{2}\left(z_{*}, t_{l}\right)\right)$, model prognostic fields in 2.5-125 m layer and also covariance functions estimated by the formulas $(6)-(8)$. 
For the second iteration, initial fields were salinity (temperature) ones reconstructed at $2.5-50 \mathrm{~m}$ layer horizons and the same initial salinity (temperature) pseudo-measurements fields in $63-125 \mathrm{~m}$ layer, but refined during the first iteration. The second and subsequent iterations were performed in the same way as the first, but with a successive shift by one horizon to the surface for the use as a basic one. Thus, at 63-125 m layer horizons, after six iterations, the corrected initial fields of salinity (temperature) pseudo-measurements were reconstructed. The last (seventh) iteration, in which $63 \mathrm{~m}$ horizon was taken as a basic one, provided the reconstruction of daily salinity (temperature) fields of pseudomeasurements at $2.5-50 \mathrm{~m}$ layer horizons.

\section{Analysis of reconstruction of salinity and temperature pseudo-measurement fields over 2012}

Average over the horizons and seasons salinity and temperature profiles reconstructed by the method of iterative pseudo-measurements were compared with similar profiles constructed on the basis of Argo measurements and the model prognostic calculation. In Fig. 2 it can be seen that the profiles of salinity pseudomeasurements in 2.5-125 m layer in the summer season of 2012, obtained as a result of iterations, are very close to the measured profiles within the main halocline, whereas in the model salinity profiles it is deeper. A quasi-homogeneous layer is distinguished near the surface, approximately the same as in the model calculation, but more pronounced than according to the data of Argo floats. The correspondence of reconstructed salinity profiles to the observations is quite satisfactory in winter, spring and autumn seasons, as well as when averaging over the year.

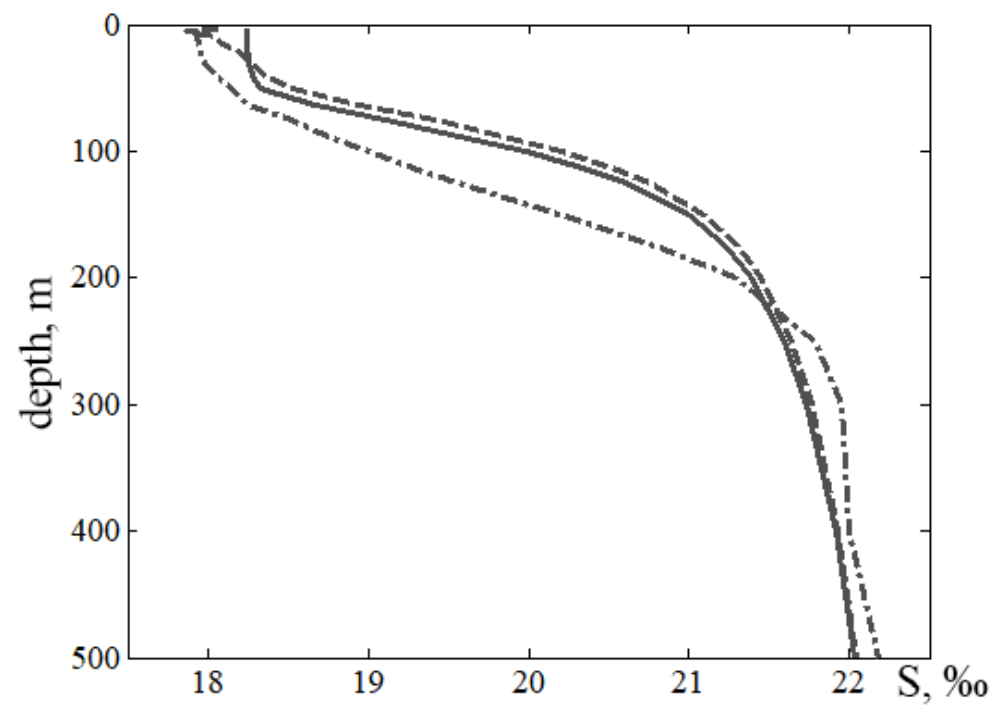

F i g. 2. Summer-average (2012) salinity profiles reconstructed using iterations (solid curve), data of Argo floats (stroke line) and model calculation (dash-dot line) 

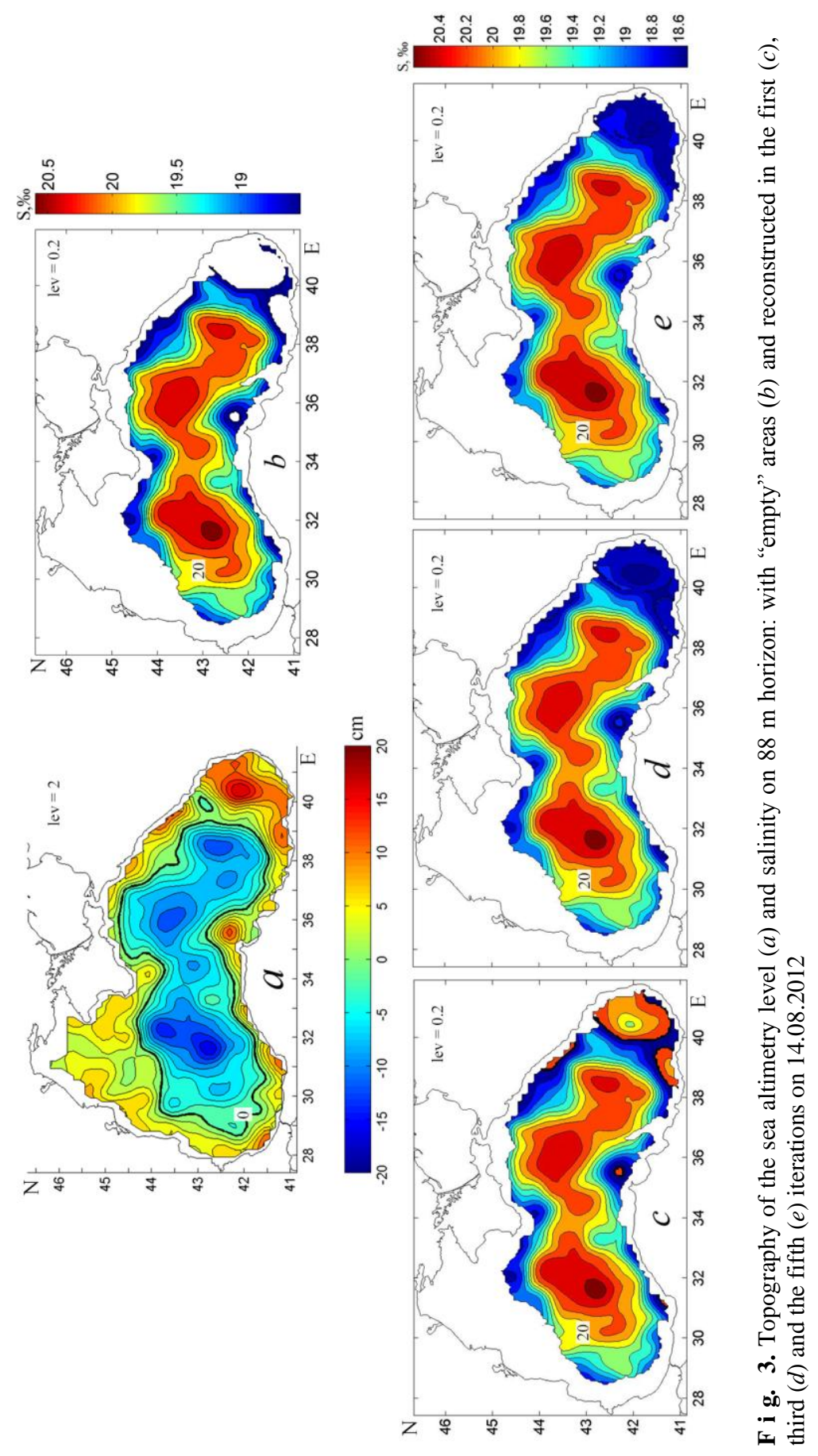
We are to analyze the field of salinity pseudo-measurements in the areas to the right of the Black Sea RC and in anticyclonic eddies. Salinity distributions are shown at $88 \mathrm{~m}$ horizon in the main halocline (Fig. 3) as an example. It can be seen that the salinity monotonously decreases towards the periphery of the region. The same tendency is clearly manifested for the Sinop and Batumi anticyclones and the one located seaward from the Caucasian coast. The magnitude of the salinity gradients corresponds to generally accepted concepts.

The features of reconstructed salinity fields at $2.5-63 \mathrm{~m}$ layer horizons are shown in Fig. 4. A monotonous decrease in salinity towards the region boundaries, which can be traced at all the given horizons, can be observed. The configuration of the eastern and western cyclonic gyres, as well as the location of cyclonic eddies at these horizons, is in good agreement with the topography of the altimetric sea level (Fig. 3, $a ; 4, d$ ). The same results were obtained when correcting and reconstructing of the fields of salinity pseudo-measurements for the winter, spring and autumn seasons.
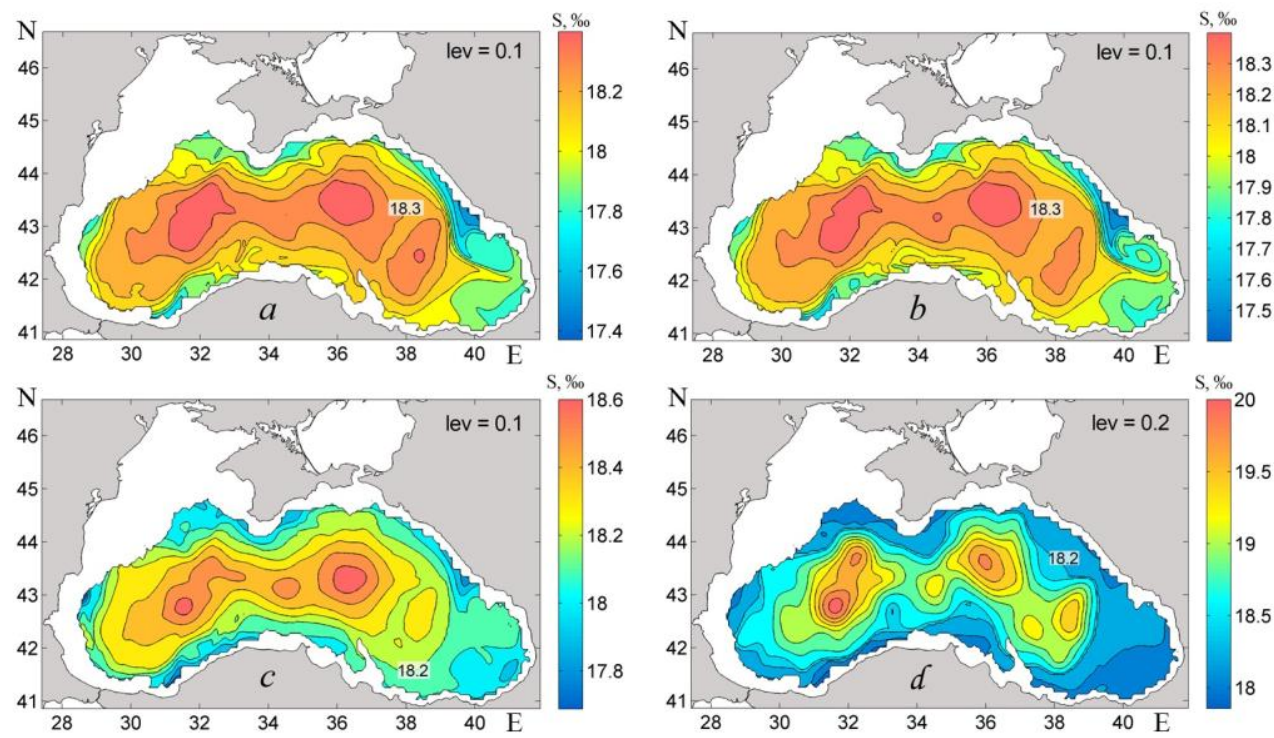

F i g. 4. Reconstructed salinity fields for 14.08 .2012 on the horizons: $10 \mathrm{~m}-a, 20 \mathrm{~m}-b, 50 \mathrm{~m}-c$ and $63 \mathrm{~m}$ (basic one) $-d$

Some problems exist only in the area occupied by the Batumi anticyclone. So, at the horizons below $63 \mathrm{~m}$, it consists of two cores (Fig. 3, e). At the same time, at the horizons of 2.5-50 m upper layer, both anticyclonic and cyclonic eddies are observed in this area. Their intensity, as is obvious from Fig. 4, is rather weak. The analysis showed that the occurrence of a low-intensity cyclonic eddy is due to the presence of the corresponding structure in the salinity field during the calculation by the model. The eddy formed in the model calculation does not coincide in phase with the measurement data of Argo and altimetry, which is reflected in the structure of the reconstructed salinity field. Despite this 
discrepancy, it can be concluded that the reconstructed salinity fields in the upper sea layer are quite satisfactory.

The quality indicators of the reconstructed fields of salinity pseudomeasurements in the sea upper layer are RMSD compared with the natural variability of salinity fields, estimated from the data of Argo buoys over the entire 2012 (Fig. 5, a). The maximum value of RMSD salinity is obtained for 63 and $75 \mathrm{~m}$ horizons and makes up $0.40 \%$, the minimum is $0.11 \%$ for $30 \mathrm{~m}$ horizon. The natural variability at $2.5-40 \mathrm{~m}$ layer horizons slightly exceeds RMSD, by about $0.02 \%$ (the same variability is observed in $250-500 \mathrm{~m}$ layer). However, in the halocline (for instance, at $88 \mathrm{~m}$ horizon), it is 1.9 times higher than RMSD. The given statistical characteristics indicate a satisfactory accuracy of the reconstructed salinity fields in $2.5-125$ m layer.

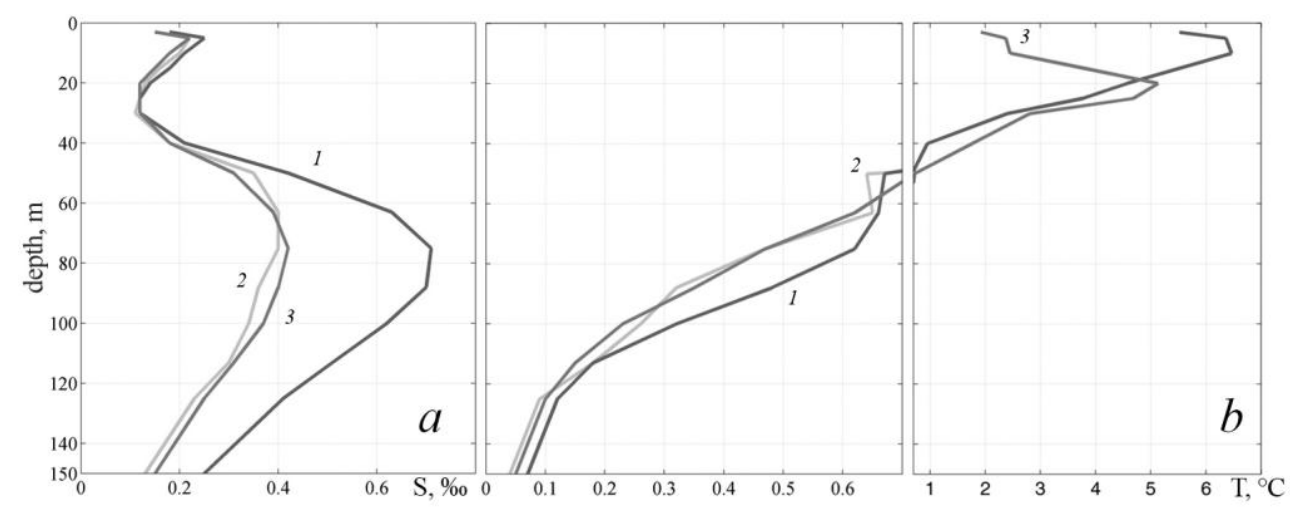

F i g. 5. Natural variability (curve 1), standard root-mean-square deviation of the reconstructed fields from the measured ones (curve 2) and that based on the reanalysis data (curve 3) for 2012 as the functions of depth for salinity $-a$ and temperature $-b$

An analysis of average over the seasons reconstructed temperature profiles revealed more noticeable discrepancy between them and the profiles constructed from the measurements, especially in 2.5-40 m near-surface. Seasonal temperature profiles can be considered satisfactory only in 50-125 m layer. Negative covariance is the formal cause for these temperature fluctuations at the basic horizon $(63 \mathrm{~m})$ with its values in the surface layer, which leads to instability of the values of interpolation coefficients. In fact, the poor quality of the algorithm for reconstructing seawater temperature indicates the predominance of the contribution of heat fluxes on the sea surface to the formation of temperature fluctuations compared to the effect of the dynamics of the deep sea layers, at least to $50 \mathrm{~m}$ depth.

In view of the foregoing, we dwell on the analysis of average annual temperature profiles (Fig. 6). It is known [17] that the subsurface water mass in the deepwater sea region is a cold intermediate layer (CIL). A comparison of model temperature profiles and the ones measured by Argo floats reveals that according 
to the model data CIL waters are located at greater depths. Average annual temperature of these waters at 50 and $63 \mathrm{~m}$ horizons was higher than one from the measurements. Average annual profiles of the temperature reconstructed in the fifth iteration ( $88 \mathrm{~m}$ basic horizon), and the ones obtained from measurements by Argo floats are the closest to each other in the integral characteristics of CIL (Fig. 6, c).
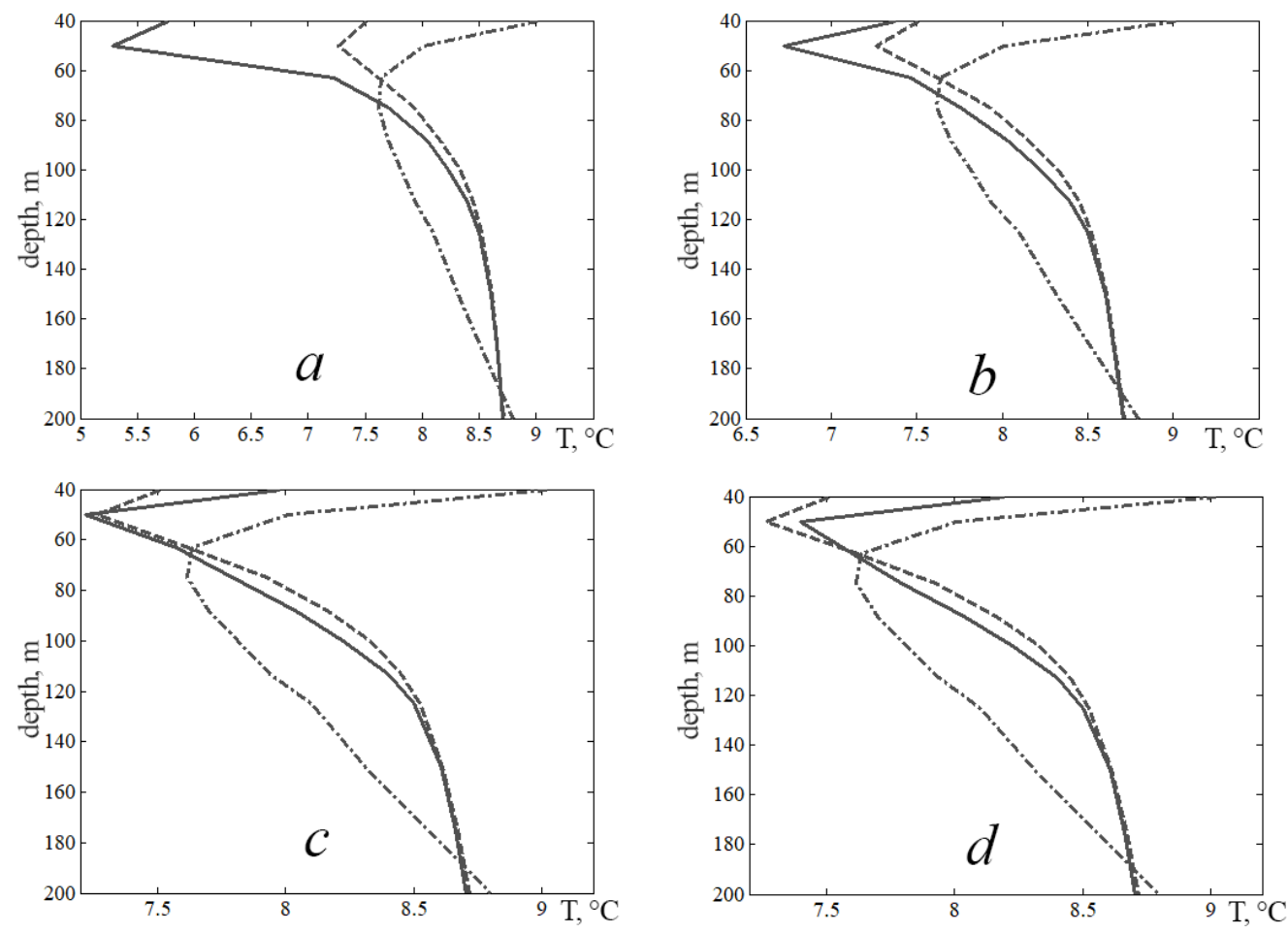

F i g. 6. Annual average profiles of temperature reconstructed by the iterations (solid line) using the data of the Argo floats measurements (stroke line) and the model calculations (dash-dot line): in the first $-a$, third $-b$, fifth $-c$ and sixth $-d$ iterations

We are to consider the reconstructed fields of temperature pseudomeasurements at 50-150 m layer horizons for mid-August 2012. Refinement of the initial temperature fields at 100, 113 and $125 \mathrm{~m}$ horizons by the iterations provided the reconstruction of the structure of Sakarya, Sinop, Batumi and two Caucasian anticyclones (Fig. 7, $a, b$ ) in the "empty" zones of the sea deepwater area. We also obtained a monotonic change in temperature towards the region periphery.

The occurrence of a cyclonic eddy in the north-eastern part of Batumi anticyclone at 50-88 m layer horizons (Fig. 7, c, d) is explained, as for the salinity field, by the effect of the cyclone obtained in the model temperature fields. To eliminate such inaccuracies, it is necessary to carry out special studies in the future. 

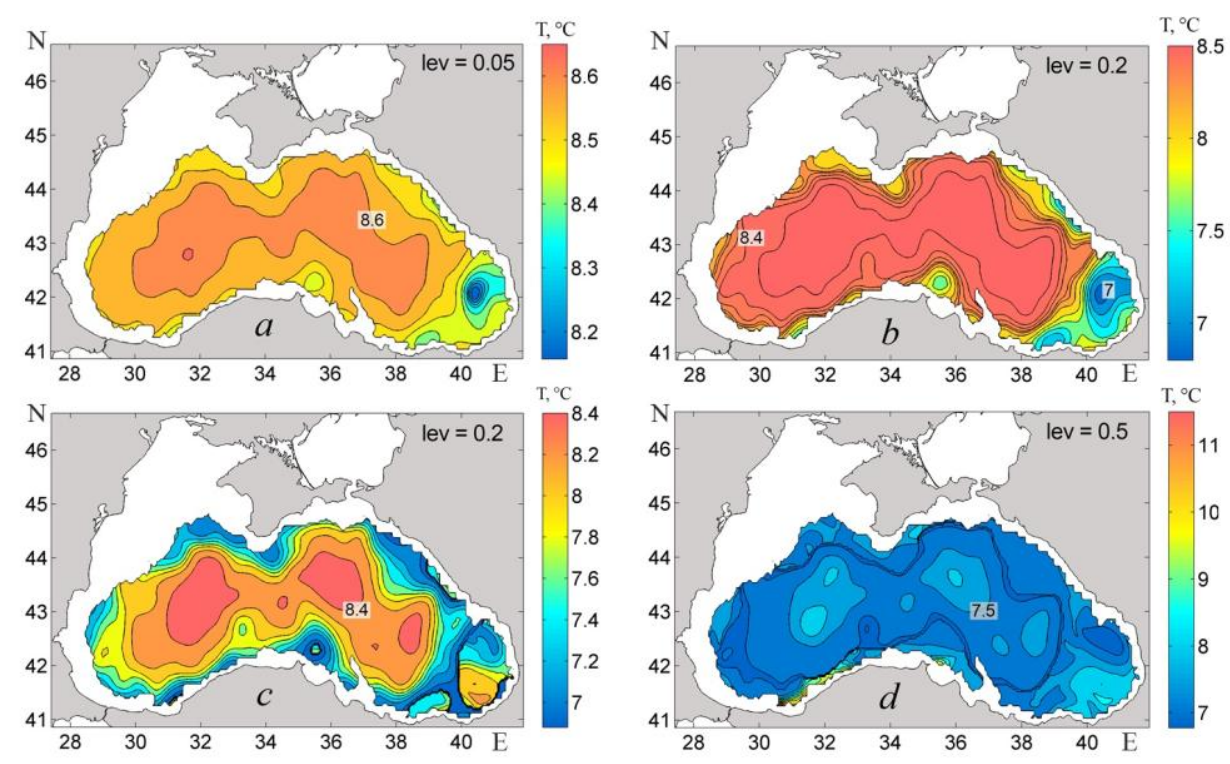

F i g. 7. Reconstructed temperature fields for 14.08 .2012 on the horizons: $150 \mathrm{~m}$ (basic one) $-a$, $113 \mathrm{~m}$ (the second iteration) $-b, 88 \mathrm{~m}$ (the fourth iteration) $-c, 50 \mathrm{~m}$ (the seventh iteration) $-d$

The trend of the variation curves by RMSD depth and the natural variability of temperature pseudo-measurements (Fig. 5, b) shows that the reconstruction accuracy of this parameter above $50 \mathrm{~m}$ is unsatisfactory. RMSD of temperature is less than natural variability at 75, 88 and $100 \mathrm{~m}$ levels. Thus, at $88 \mathrm{~m}$ depth the natural variability of measured temperature fields is 1.5 times higher than the reconstructed temperature fields. At $63 \mathrm{~m}$ horizon and below $100 \mathrm{~m}$, RMSD is comparable with the value of natural variability.

An iterative method for refining the previously obtained initial fields of salinity and temperature pseudo-measurements makes it possible to reconstruct thermohaline parameters in the "empty" areas. That will bring the range of the model sea level in the calculations with the assimilation of reconstructed salinity and temperature fields closer to the range of the altimetric level.

\section{Reanalysis of the sea hydrophysical fields over 2012 by assimilating temperature and salinity pseudo-measurements in MHI model}

The efficiency of use of the above-described three-dimensional temperature and salinity arrays is estimated on the basis of their assimilation in the water circulation model. Currently, in the oceanology two approaches to the development and successful application of algorithms for the assimilation of available measurement data in the circulation models are the most promising: variational (4D-Var [18-20]) and Ensemble Kalman Filter approach. The latter is subdivided into an extended Ensemble Kalman Filter (EnKF [21, 22]) and Ensemble Optimal Interpolation (EnOI [23]). We also note the work [24], in which the algorithm for assimilating temperature and salinity monthly average climatic fields of the Black and Azov Seas was developed and practically implemented in the "variational initialization - forecast" mode. However, the practical implementation of these 
approaches requires powerful computational resources. This is especially true for $4 D$-Var method due to its computational complexity, which consists in iterative solving of a boundary value problem for a system of direct and adjoint equations. More simple methods based on optimal interpolation (OI, EnOI, 3D-Var [22, 23, 4]) have the disadvantage that the forecast error statistics is recorded a priori. To overcome these drawbacks, various simplifications of Kalman Filter implementation are used.

In this work, we used the reconstructed three-dimensional temperature and salinity fields in 2.5-500 m layer for the reanalysis of the Black Sea hydrophysical fields for 2012 through their assimilation in MHI model using the adaptive statistics method [9, 13]. A detailed description of MHI model is given in [10]. Note that the coefficients of the turbulent exchange of momentum and the diffusion of heat and salt were calculated along the vertical using Pacanowsci - Philander parameterization [25].

The basis of the adaptive statistics method consists of: differential equations of dispersion of forecast errors for salinity $\left(\sigma_{S}^{2}(\vec{x}, t)\right)$ and temperature $\left(\sigma_{T}^{2}(\vec{x}, t)\right)$ with optimally selected relaxation coefficient (REL) [13], the sources in the transport equations are heat and salt diffusions $[26,13]$, and formulas for correcting forecast errors dispersions after the assimilation of pseudo-measurements in the model [13].

Here we represent differential equation and correlation for salinity forecast error dispersion (function arguments are omitted) in the following form:

$$
\begin{gathered}
\frac{\partial \sigma_{\mathrm{S}}^{2}}{\partial t}+\frac{\partial \sigma_{S}^{2} u}{\partial x}+\frac{\partial \sigma_{S}^{2} v}{\partial y}+\frac{\partial \sigma_{S}^{2} w}{\partial z}=\frac{\partial}{\partial z} k^{S} \frac{\partial \sigma_{S}^{2}}{\partial z}+k_{H} \Delta \sigma_{S}^{2}+\operatorname{REL}^{-1}\left(\sigma_{* S}^{2}-\sigma_{S}^{2}\right), \\
Q_{S}=\frac{\sigma_{\mathrm{S}}^{2}}{\operatorname{REL}\left[\sigma_{\mathrm{S}}^{2}+\gamma(\mathrm{z}) \sigma_{\mathrm{errS}}^{2}\right]}\left[S^{\mathrm{obs}}-S^{\mathrm{m}}\right], \\
\sigma_{\mathrm{S}}^{2^{*}}=\sigma_{\mathrm{S}}^{2}-\frac{\sigma_{\mathrm{S}}^{2} \sigma_{\mathrm{S}}^{2}}{\left[\sigma_{\mathrm{S}}^{2}+\sigma_{\mathrm{errS}}^{2}\right]} \approx \frac{\sigma_{\mathrm{S}}^{2} \sigma_{\mathrm{erS}}^{2}}{\left[\sigma_{\mathrm{S}}^{2}+\gamma(z) \sigma_{\mathrm{errS}}^{2}\right]} .
\end{gathered}
$$

In equation (9) $u, v, w$ are the components of the current velocity vector by the axes of the Cartesian coordinate system; $k^{S}$ the coefficient of vertical turbulent exchange (calculated by the model from [10]); $k_{H}$ is a coefficient of horizontal turbulent diffusion $\left(k_{H}=10^{5} \mathrm{~cm}^{2} / \mathrm{s}\right.$ ); $\Delta$ is the Laplace operator; the last term of the right side is a source reflecting the relaxation of the calculated dispersion (REL = 10 days [13]) to the seasonally varying (for a conditional year) typical dispersion of salinity forecast errors $\sigma_{* S}^{2}(\vec{x}, t)$. The latter was estimated according to the model calculation carried out for 1993-2012 period using ERA-Interim atmospheric forcing [27].

The assessment algorithm and the analysis of seasonal variance of typical salinity (temperature) dispersion average daily values are presented in [13]. In relations (10), (11) $Q_{S}$ is the source in the salt transport - diffusion equation; REL1 is a relaxation parameter equal to 12 hours [13]; $\sigma_{S}^{2^{*}}$ is corrected error 
dispersion; $\quad \gamma(z) \sigma_{\text {errs }}^{2}$ is a product of an empirically selected parameter $(\gamma(z) \leq 0,015)$ by the monthly average dispersion of errors in the reconstruction of salinity pseudo-measurements $S^{\text {obs }} ; S^{\mathrm{m}}$ is a model salinity. The difference between the first cofactor in the source (10) and that used in [26] is that it depends on the dispersion of the salinity forecast errors changing over the time.

Boundary and initial conditions for 01.01.2012 for the equation (9) are given in [13]. The type of the differential equation for the dispersion of temperature forecast errors, boundary and initial conditions, and the form of relations (10), (11) are the same as for the dispersion of the salinity forecast errors. Two equations of the form (9) were solved numerically, together with the thermohydrodynamic equations of the model. Assimilation of salinity (temperature) pseudomeasurements in the model, as well as the correction of the form (11), was performed at each time step.

Now we focus on the results of the reanalysis of the sea hydrophysical fields for 2012. Average over the year salinity RMSD according to the reanalysis data and RMSD from the proposed technique are close to each other (Fig. 5, a). Rootmean-square deviations of salinity according to the reanalysis data, compared to RMSD of salinity pseudo-measurements, are slightly less at the horizons of 2.5-63 m layer, and in 75-500 m layer they are slightly higher. According to the reanalysis data, the maximum value of the annual salinity RMSD is $0.42 \%$ at $75 \mathrm{~m}$ horizon. This is by $0.06 \%$ less than the maximum value of the averaged salinity RMSD over the entire reanalysis array for 1993-2012, performed with assimilation of altimetry data and sea-surface temperatures in the MHI model using the equations and turbulence relations from Mellor-Yamada family of models [28]. What is important is that square root of the dispersion of salinity fields measured by the Argo floats in 50-200 m layer significantly exceeds RMSD of the reconstructed fields of salinity pseudo-measurements and calculated in the reanalysis for 2012 (Fig. 5, a).

According to the reanalysis data, the annual RMSD of temperature at $2.5-40 \mathrm{~m}$ layer horizons are very high, since the pseudo-measurements in this layer were not assimilated. The maximum value of temperature RMSD is $5.13^{\circ} \mathrm{C}$ at $20 \mathrm{~m}$ horizon (Fig. 5, b). This reflects that thermodynamics of the sea upper layer is reconstructed unsatisfactorily. In Fig. 5, $b$, it can be seen that the annual profiles of temperature RMSD in 50-200 m layer, constructed according to the reanalysis data and measurements, and the profiles of reconstructed fields of temperature pseudomeasurements are close and alternate with each other. Most likely, the causes for high values of temperature RMSD in our calculation are inaccuracies in the assignment of heat fluxes from the atmosphere. Obviously, the best result can be achieved by assimilating satellite observations of the sea surface temperature. However, it should be noted that even with the assimilation of sea-surface temperature in the $\mathrm{MHI}$ model, the maximum value of averaged temperature RMSD for summer, according to the reanalysis from [28], is $3.4^{\circ} \mathrm{C}$ at $\approx 18 \mathrm{~m}$ depth, which is exclusively due to the aggravated seasonal thermocline in the Black Sea. 
Comparison of diagrams in Fig. 8 shows that the assimilation of pseudomeasurements of the thermohaline parameters reconstructed in this work provided a good reconstruction of the CIL at the sea. However, its cold content turned out to be somewhat smaller than that obtained in the reanalysis from [29]. According to [30], in 2012, the normalized anomalies of shelf waters heat content (in fact, of the open sea) were negative. Therefore, this year is characterized, in accordance with the scale adopted in [30], by a high degree of CIL waters renewal. An increase in the CIL cold content can be obtained by assimilating the sea surface temperature measured from Artificial Earth Satellites (AES).

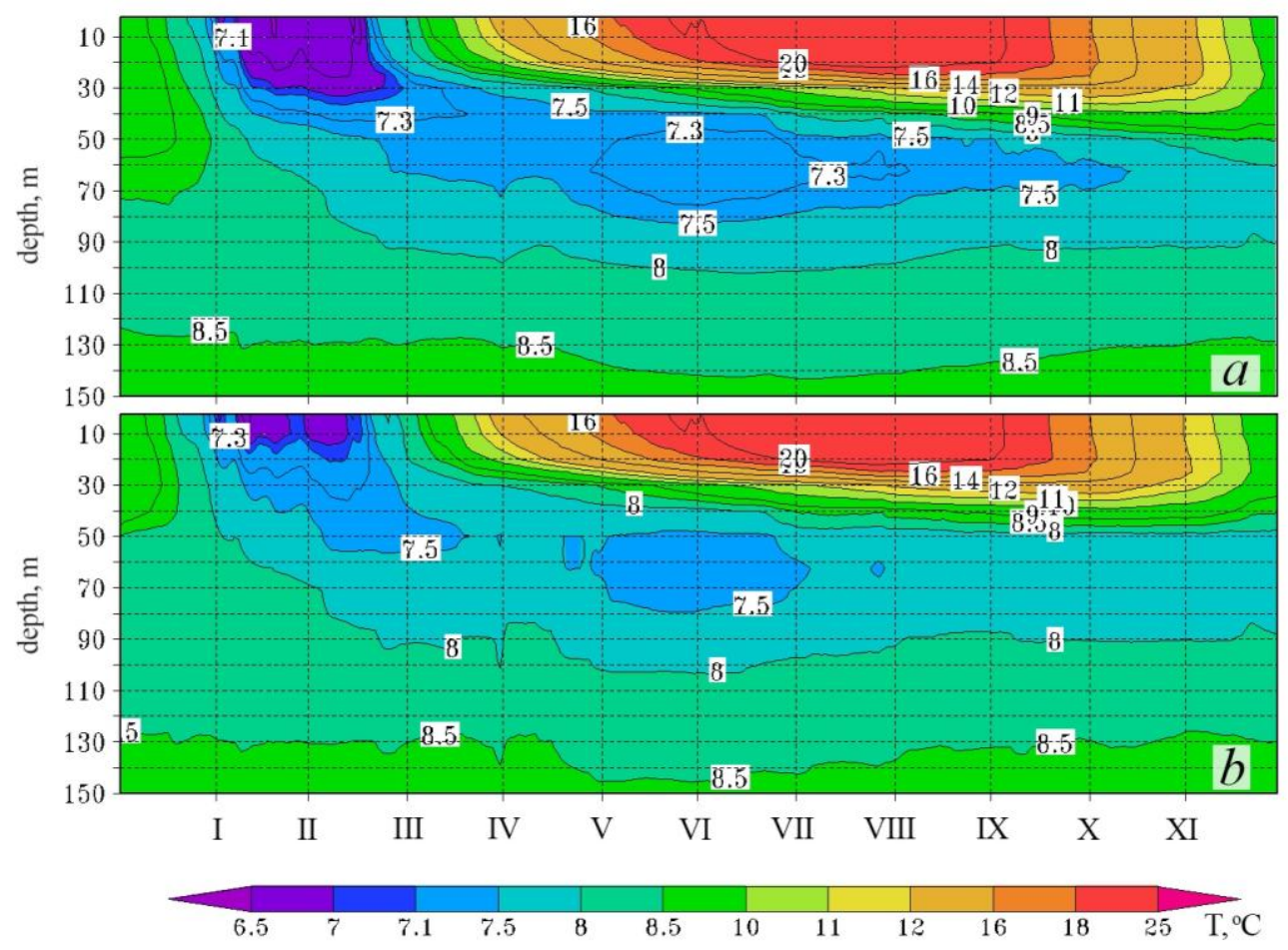

F i g. 8. Diagram of seasonal variability of the horizons-average daily temperature based on the reanalysis for 2012 with model assimilation of: temperature and salinity pseudo-measurements in the 63-500 m layer [9] $-a$; with the reconstructed pseudo-measurements of temperature in the 50-500 m layer and salinity in the $2.5-500 \mathrm{~m}$ layer $-b$

Let us refer to Fig. 9, which is given for comparing the structures of free sea surface elevation fields. A benchmark is the altimetry level surface. The configuration and local structures of the sea level, shown in Fig. 9, $b$, differ from similar characteristics that determine the topography of the altimetry level (Fig. 9, a). A noticeable difference is observed between the structures of Batumi and Caucasian anticyclones. The intensity of Sinop anticyclonic eddy in Fig. 9, $b$ is significantly lower than in the altimetry sea level. Sevastopol anticyclone is very 
diffuse in this figure and in the central part of the basin only the western and eastern cyclonic gyres are observed. A difference of the discussed level is $25 \mathrm{~cm}$.
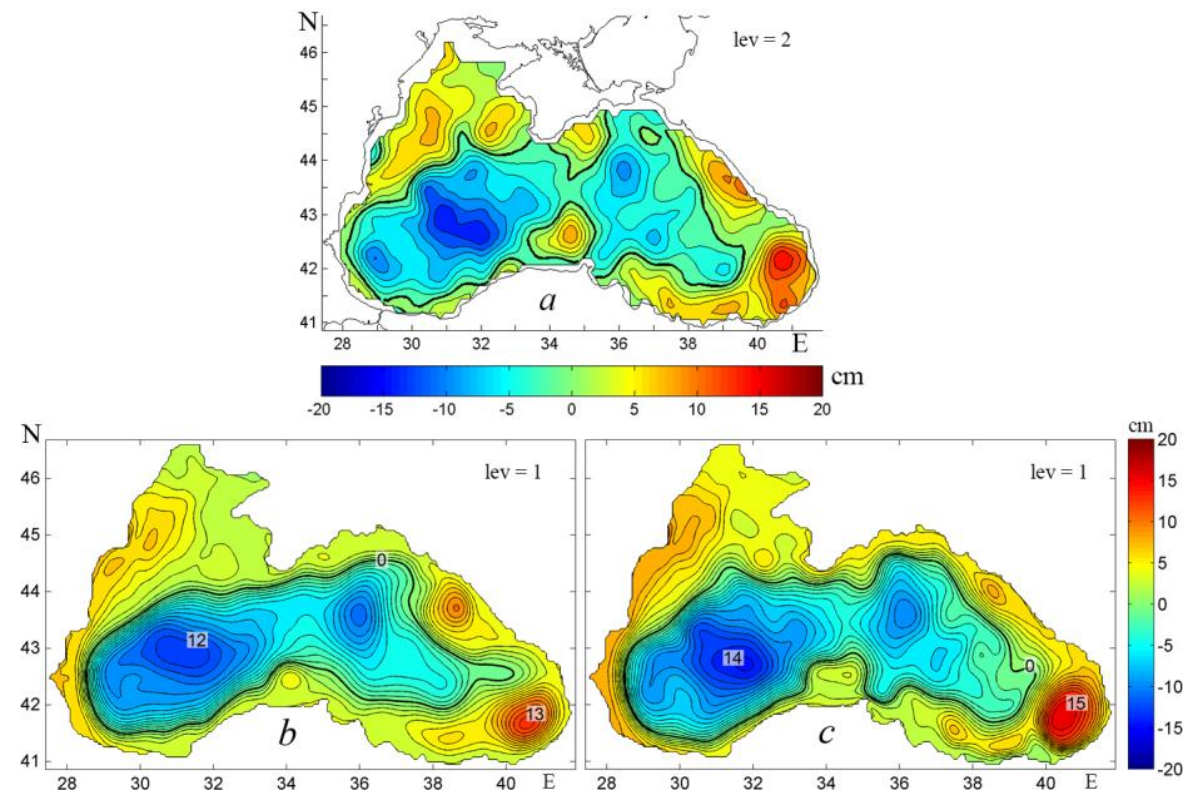

F i g. 9. Topography of the sea level for 15.06.2012: altimetry one $-a$, that resulted from the reanalysis with model assimilation of the uncorrected pseudo-measurements of temperature and salinity in the 63-500 m layer [9] $-b$ and the corrected pseudo-measurements of temperature in the 50-500 m layer and salinity in the 2.5-500 m layer $-c$

CIL configuration in the reanalysis with assimilation in the model of corrected pseudo-measurements reconstructed in 2.5-63 m upper layer, as well as the location of cyclonic eddies in the center of the sea and anticyclones to the right of the Black Sea RC, are much closer to the topography of the altimetry sea level (Fig. 9, $a, c$ ). The structure and intensity of Kizilirmak, Batumi, and Caucasian anticyclones are very close to similar eddy formations in the altimetry level. The intensity of the Sinop and Sevastopol anticyclones was not quite sufficient. The difference in the analyzed level is $29 \mathrm{~cm}$, which is $2 \mathrm{~cm}$ lower than in the altimetry level. The assimilation of corrected temperature and salinity pseudomeasurements in the model in any other months of 2012 improves the structure of the calculated level fields, bringing it closer to the structure of the altimetry sea level.

For a quantitative assessment of the reliability of the sea level reconstructed in the model relative to the altimetry level, seasonal variability of RMSD calculated in the deepwater area for four numerical experiments is given in Fig. 10. RMSD values assessed by model calculation prevail. RMSD values according to the reanalysis carried out in [31] (curve 2) from January to April and from mid-July to mid-August exceed the sea level RMSD reconstructed in our two reanalyses (curves 3, 4). In June and September, they differ little (increasing or decreasing) from level RMSD calculated by us. In May, October and December, RMSD level values, according to the reanalysis from [31], are less than those we obtained. 
Curve 3 in Fig. 10 reflects seasonal variability of the sea level RMSD calculated by us in the reanalysis for 2012 using the adaptive statistics method with the assimilation in the model of uncorrected temperature and salinity pseudomeasurements in 63-500 m layer. Curve 4 corresponds to the behavior of level RMSD reconstructed in the reanalysis of this work. It is obvious that curve 4 is located mainly below the curve 3 . This means that the sea level reconstructed in the reanalysis of this work in the deepwater area is qualitatively and quantitatively closer to the altimetry level.

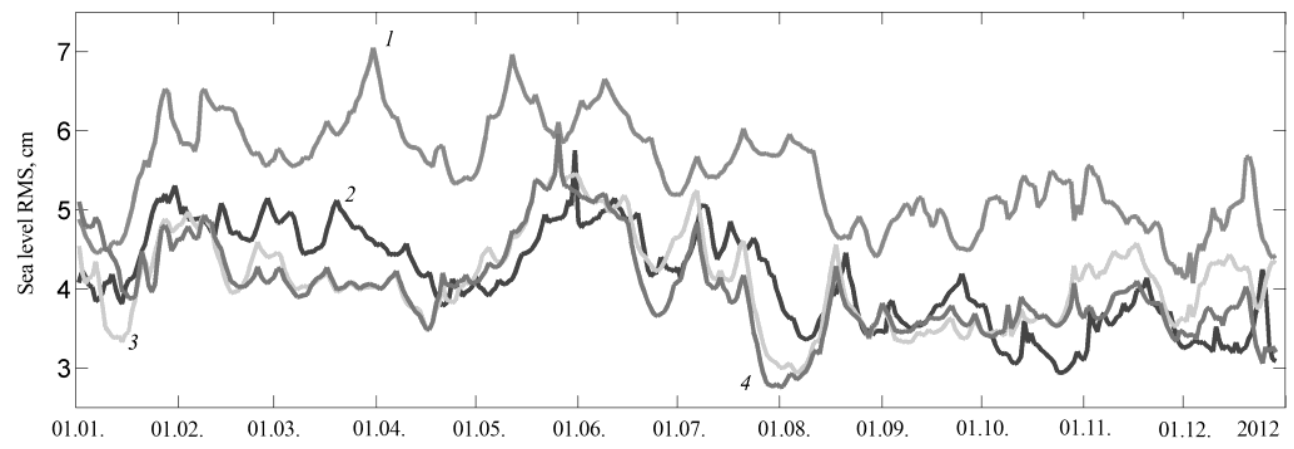

F i g. 10. Seasonal variability of root-mean-square deviation of the sea level reconstructed for 2012 (comparison with the altimetry one) based on four calculations: the model one (curve 1) and the reanalyses ones from [31] (curve 2), [9] (curve 3) and the present paper (curve 4)

\section{Discussion}

The present work in a certain sense completes the study of the possibility of reconstructing the three-dimensional seawater temperature and salinity fields based on altimetry measurements and a small number of temperature and salinity profile observations $[6,7]$. It shows that in this case the seawater temperature and salinity three-dimensional fields in the main pycnocline are reconstructed with fairly high accuracy throughout the deepwater part of the Black Sea. At the same time, the reconstructed seawater salinity has a good accuracy even in the upper mixed layer of the sea. Unfortunately, the seawater temperature cannot be reconstructed with a good accuracy in the surface layer, obviously, due to significant variability during the heat fluxes on the sea surface.

The motivation for carrying out research in this direction was a small number of hydrological observations in the Black Sea during the entire time when altimetry observations became available. When assimilating small amounts of data on the haline and thermal stratification of the sea in the water circulation models, significant errors occur. In addition, during the long-term calculations, noticeable trends are observed in the temperature and salinity fields in the main pycnocline. The use of three-dimensional arrays of seawater temperature and salinity, reconstructed according to altimetry, allows us to get rid of these problems.

The studies in this paper have been carried out for the Black Sea, but they are of wider significance. Since the time of POLYMODE, it is known that in oceanic areas of considerable length the first mode of decomposition of temperature and salinity field deviations into empirical orthogonal functions describes about $80 \%$ of 
the vibrational energy of isopycnic, isothermal and isochaline surfaces relative to their equilibrium state. This circumstance is a reflection of adiabatic nature of synoptic processes in the ocean environment and the predominance of the first dynamic mode. In fact, the altimetry assimilation method in $[32,33]$ is based on such a feature of marine dynamics. Therefore, the approach proposed in this paper can be effective for other marine areas, such as marginal seas of oceanic type and oceanic cycles, where relatively homogeneous water masses are observed. In particular, it is possible to improve the accuracy of the reanalysis of the World Ocean fields on its basis for the time period when the observations from Argo floats were not yet available.

\section{REFERENCES}

1. Drévillon, M., Bourdallé-Badie, R., Derval, C., Lellouche, J. M., Rémy, E., Tranchant, B., Benkiran, M., Greiner, E. and Guinehut, S. [et al.], 2008. The GODAE/Mercator-Ocean Global Ocean Forecasting System: Results, Applications and Prospects. Journal of Operational Oceanography, [e-journal] 1(1), pp. 51-57. doi:10.1080/1755876X.2008.11020095

2. Dorofeev, V.L. and Sukhikh, L.I., 2016. Analysis of Variability of the Black Sea Hydrophysical Fields in 1993-2012 Based on the Reanalysis Results. Physical Oceanography, [e-journal] (1), pp. 33-47. doi:10.22449/1573-160X-2016-1-33-47

3. Dorofeev, V.L. and Sukhikh, L.I., 2017. Modelling of Long-Term Evolution of Hydrophysical Fields of the Black Sea. Oceanology, [e-journal] 57(6), pp. 784-796. doi:10.1134/S0001437017060017

4. Lemieux-Dudon, B., Storto, A., Ciliberti, S.A., Peneva, E., Özsoy, E., Coppin, G., Masina, S. and Pinardi, N., 2018. The Black Sea Physical Reanalysis System for the Copernicus Marine Service: Description and Skill Assessment. In: EGU Assembly, 2018. Geophysical Research Abstracts. EGU General Assembly. Vol. 20. EGU2018-19742. Available at: https://meetingorganizer.copernicus.org/EGU2018/EGU2018-19742.pdf [Accessed: 20 May 2019].

5. Roemmich, D., Johnson, G.C., Riser, S., Davis, R., Gilson, J., Owens, W.B., Garzoli, S.L., Schmid, C. and Ignaszewski, M., 2009. The Argo Program: Observing the Global Ocean with Profiling Floats. Oceanography, [e-journal] 22(2), pp. 34-43. https://doi.org/10.5670/oceanog.2009.36

6. Korotaev, G.K., Lishaev, P.N. and Knysh, V.V., 2015. Technique of the Black Sea Temperature and Salinity Measurement Data Analysis Using Dynamic Altimetry Level. Physical Oceanography, [e-journal] (2), pp. 24-38. doi:10.22449/1573-160X-2015-2-24-38

7. Korotaev, G.K., Lishaev, P.N. and Knysh, V.V., 2016. Reconstruction of the ThreeDimensional Salinity and Temperature Fields of the Black Sea on the Basis of Satellite Altimetry Measurements. Izvestiya, Atmospheric and Oceanic Physics, [e-journal] 52(9), pp. 961-973. doi:10.1134/S0001433816090152

8. Knysh, V.V. and Lishaev, P.N., 2016. Improvement of the Method for Reconstructing the Temperature and Salinity Three-Dimensional Fields of the Black Sea Based on Insufficient Measurements and Altimetry. Physical Oceanography, [e-journal] (6), pp. 3-14. doi:10.22449/1573-160X-2016-6-3-14

9. Lishaev, P.N., Knysh, V.V. and Korotaev, G.K., 2018. Reproduction of Variability of the Black Sea Level and Pycnocline Characteristics Based on the Adaptive Statistics Method. Physical Oceanography, [e-journal] 25(4), pp. 251-261. doi:10.22449/1573-160X2018-4-251-261

10. Lishaev, P.N., Korotaev, G.K., Knysh, V.V., Mizyuk, A.I. and Dymova, O.A., 2014. Vosstanovlenie Sinopticheskoy Izmenchivosti Gidrofizicheskikh Poley Chernogo Morya na Osnove Reanaliza za 1980-1993 Gody [Reproduction of Synoptic Variability of the Black Sea Hydrophysical Fields Based on Reanalysis for 1980-1993]. Morskoy Gidrofizicheskiy Zhurnal, (5), pp. 49-68 (in Russian).

11. Agoshkov, V.I., Parmuzin, E.I. and Shutyaev, V.P., 2013. Observational Data Assimilation in the Problem of Black Sea Circulation and Sensitivity Analysis of its Solution. Izvestiya. 
Atmospheric and Oceanic Physics, [e-journal] 49(6), pp. 592-602. doi:10.1134/S0001433813060029

12. Zalesny, V.B., Diansky, N.A., Fomin, V.V., Moshonkin, S.N., Demyshev, S.G., 2012. Numerical Model of the Circulation of the Black Sea and the Sea of Azov. Russian Journal of Numerical Analysis and Mathematical Modelling, [e-journal] 27(1), pp. 95-112. doi:10.1515/rnam-2012-0006

13. Korotaev, G.K., Knysh, V.V., Lishaev, P.N. and Demyshev, S.G., 2018. Application of the Adaptive Statistics Method for Reanalysis of the Black Sea Fields Including Assimilation of the Temperature and Salinity Pseudo-Measurements in the Model. Physical Oceanography, [e-journal] 25(1), pp. 36-51. doi:10.22449/1573-160X-2018-1-36-51

14. Gandin, L.S. and Kagan, R.L., 1976. Statisticheskie Metody Interpretatsii Meteorologicheskikh Dannykh [Statistical Methods for the Interpretation of Meteorological Data]. Leningrad: Gidrometeoizdat, 357 p. (in Russian).

15. Korotaev, G.K., Saenko, O.A., Koblinsky, C.J., Demyshev, S.G. and Knysh, V.V., 1998. Otsenka Tochnosti, Metodologiya i Nekotoryye Rezul'taty Usvoyeniya Al'timetricheskikh Dannykh TOPEX/POSEYDON v Modelyakh Obshchey Tsirkulyatsii Chernogo Morya [An Accuracy, Methodology, and Some Results of the Assimilation of the TOPEX/POSEYDON Altimetry Data into the Models of the Black Sea General Circulation]. Earth Research from Space, (3), pp. 3-17 (in Russian).

16. Korotaev, G.K., Saenko, O.A. and Koblinsky, C.J., 2001. Satellite Altimetry Observation of the Black Sea Level. Journal of Geophysical Research: Oceans, [e-journal] 106(C1), pp. 917-933. doi:10.1029/2000JC900120

17. Ivanov, V.A. and Belokopytov, V.N., 2011. Oceanography of the Black Sea. Sevastopol: ECOSI-Gidrofizika, $212 \mathrm{p}$

18. Agoshkov, V.I., Ipatova, V.M., Zalesnyi, V.B., Parmuzin, E.I. and Shutyaev, V.P., 2010. Problems of Variational Assimilation of Observational Data for Ocean General Circulation Models and Methods for Their Solution. Izvestiya. Atmospheric and Oceanic Physics, [ejournal] 46(6), pp. 677-712. doi:10.1134/S0001433810060034

19. Agoshkov, V.I., Parmuzin, E.I. and Shutyaev, V.P., 2013. Observational Data Assimilation in the Problem of Black Sea Circulation and Sensitivity Analysis of its Solution. Izvestiya. Atmospheric and Oceanic Physics, [e-journal] 49(6), pp. 592-602. doi:10.1134/S0001433813060029

20. Zalesny, V.B. and Ivchenko, V.O., 2015. Simulating Large-Scale Circulation in Seas and Oceans. Izvestiya. Atmospheric and Oceanic Physics, [e-journal] 51(3), pp. 259-271. doi:10.1134/S0001433815030135

21. Evensen, G., 2003. The Ensemble Kalman Filter: Theoretical Formulation and Practical Implementation. Ocean Dynamics, [e-journal] 53(4), pp. 343-367. doi:10.1007/s10236-0030036-9

22. Belyaev, K.P., Tanajura, C.A.S. and Tuchkova, N.P., 2012. Comparison of Methods for Argo Drifters Data Assimilation into a Hydrodynamical Model of the Ocean. Oceanology, [e-journal] 52(5), pp. 593-603. doi:10.1134/S0001437012050025

23. Kaurkin, M.N., Ibrayev, R.A. and Belyaev, K.P., 2016. ARGO Data Assimilation into the Ocean Dynamics Model with High Spatial Resolution Using Ensemble Optimal Interpolation (EnOI). Oceanology, [e-journal] 56(6), pp. 774-781. doi:10.1134/S0001437016060059

24. Zalesny, V.B., Gusev, A.V. and Moshonkin, S.N., 2013. Numerical Model of the Hydrodynamics of the Black Sea and the Sea of Azov with Variational Initialization of Temperature and Salinity. Izvestiya. Atmospheric and Oceanic Physics, [e-journal] 49(6), pp. 642-658. doi:10.1134/S0001433813060133

25. Pacanowsci, R.C. and Philander, S.G.H., 1981. Parameterization of Vertical Mixing in Numerical Models of Tropical Oceans. Journal of Physical Oceanography, [e-journal] 11(11), pp. 1443-1451. https://doi.org/10.1175/15200485(1981)011<1443:POVMIN>2.0.CO;2

26. Sarmiento, J.L. and Bryan, K., 1982. An Ocean Transport Model for the North Atlantic. Journal of Geophysical Research: Oceans, [e-journal] 87(C1), pp. 394-408. https://doi.org/10.1029/JC087iC01p00394 
27. Dee, D.P., Uppala, S.M., Simmons, A.J., Berrisford, P., Poli, P., Kobayashi, S., Andrae, U., Balmaseda, M.A., Balsamo, G. [et al.], 2011. The ERA-Interim Reanalysis: Configuration and Performance of the Data Assimilation System. Quarterly Journal of the Royal Meteorological Society, 137(656), pp. 553-597. doi:10.1002/qj.828

28. Sukhikh, L.I. and Dorofeyev, V.L., 2018. Influence of the Vertical Turbulent Exchange Parameterization on the Results of Reanalysis of the Black Sea Hydrophysical Fields. Physical Oceanography, [e-journal] 25(4), pp. 262-279. doi:10.22449/1573-160X2018-4-262-279

29. Dorofeev, V.L. and Sukhikh, L.I., 2016. Analysis of Variability of the Black Sea Hydrophysical Fields in 1993-2012 Based on the Reanalysis Results. Physical Oceanography, [e-journal] (1), pp. 33-47. doi:10.22449/1573-160X-2016-1-33-47

30. Ilyin, Yu.P., Repetin, L.N., Belokopytov, V.N., Goryachkin, Yu.N., Dyakov, N.N., Kubryakov, A.A. and Stanichnyi, S.V., 2012. Gidrometeorologicheskiye Usloviya Morey Ukrainy. Tom 2. Chernoye More [Hydrometeorological Conditions of the Seas of Ukraine. Vol. 2. Black Sea]. Sevastopol, 421 p. (in Russian).

31. Dorofeev, V.L. and Sukhikh, L.I., 2017. Study of Long-Term Variability of Black Sea Dynamics on the Basis of Circulation Model Assimilation of Remote Measurements. Izvestiya, Atmospheric and Oceanic Physics, [e-journal] 53(2), pp. 224-232. doi:10.1134/S0001433817020025

32. Mellor, G.L. and Ezer, T., 1991. A Gulf Stream Model and an Altimetry Assimilation Scheme. Journal of Geophysical Research: Oceans, [e-journal] 96(C5), pp. 8779-8795. https://doi.org/10.1029/91JC00383

33. Knysh, V.V., Saenko, O.A. and Sarkisyan, A.S., 1996. Method of Assimilation of Altimeter Data and Its Test in the Tropical North Atlantic. Russian Journal of Numerical Analysis and Mathematical Modelling, [e-journal] 11(5), pp. 393-409. https://doi.org/10.1515/rnam.1996.11.5.393

About the authors:

Pavel N. Lishaev - Junior Research Associate, Marine Hydrophysical Institute of RAS (2 Kapitanskaya Str., Sevastopol, 299011, Russian Federation), Scopus Author ID: 57193071072, pavellish@mail.ru

Vasiliy V. Knysh - Leading Research Associate, Marine Hydrophysical Institute of RAS (2 Kapitanskaya Str., Sevastopol, 299011, Russian Federation), Dr.Sci. (Phys.-Math.), professor, ResearcherID: B-3603-2018, vaknysh@yandex.ru

Gennadiy K. Korotaev - Scientific Supervisor, Marine Hydrophysical Institute of RAS (2 Kapitanskaya Str., Sevastopol, 299011, Russian Federation), corresponding member of RAS, Sci.Dr. (Phys.-Math.), professor, ResearcherID: K-3408-2017, gkorotaev@ gmail.com

Contribution of the co-authors:

Pavel N. Lishaev - data preparation, carrying out numerical experiments, analysis of results, validation of results, preparation of graphic materials

Vasiliy V. Knysh - development of an algorithm for temperature and salinity reconstruction in the Black Sea upper layer according to pseudo-measurements, analysis of the results of numerical experiments, preparation of the paper text

Gennadiy K. Korotaev - statement of the problem, analysis and synthesis of the research data, correction of the paper, consulting support

All the authors have read and approved the final manuscript.

The authors declare that they have no conflict of interest. 